\title{
Flavones as Natural Photoinitiators for Light Mediated Free- Radical Polymerization via Light Emitting Diodes
}

\author{
Assi Al Mousawi ${ }^{\mathrm{a}}$, Patxi Garra ${ }^{\mathrm{a}}$, Frédéric Dumur* ${ }^{\mathrm{b}}$, Bernadette Graff ${ }^{\mathrm{a}}$, Jean Pierre Fouassier ${ }^{\mathrm{a}}$, \\ Jacques Lalevée $*^{\mathrm{a}}$ \\ ${ }^{\text {a } I n s t i t u t ~ d e ~ S c i e n c e ~ d e s ~ M a t e ́ r i a u x ~ d e ~ M u l h o u s e ~ I S 2 M ~-~ U M R ~ C N R S ~} 7361$ - UHA, 15, rue \\ Jean Starcky, 68057 Mulhouse Cedex, France. \\ ${ }^{\mathrm{b}}$ Aix Marseille Univ, CNRS, ICR UMR 7273, F-13397 Marseille, France.
}

Corresponding authors: jacques.lalevee@uha.fr; frederic.dumur@univ-amu.fr

\begin{abstract}
:
In this work, we propose the use of flavones that can be derived from natural products as versatile high performance visible light photoinitiators initially with amino acid and later with iodonium salt and phosphinobenzoic acid combinations for free radical polymerization (FRP) acrylates of thin samples (25 microns) and methacrylates thick samples (1.4 mm) upon near UV light or visible light exposure using Light Emitting Diodes LED@385nm and LED@405nm. High polymerization initiating abilities are found with different Hydroxyflavones and high final reactive function conversions are obtained. Their utilization as materials for 3D printing is especially carried out for $1 \mathrm{~mm}$ thick 3D printed photopolymers. A full picture of the included photochemical mechanisms is additionally given.
\end{abstract}

Keywords: Free radical polymerization; Light Emitting Diodes (LEDs); photoinitiators; 3D printing, flavones 


\section{Introduction:}

Exponential growth of photopolymerization applications have been witnessed in the last decade: from historical niche coatings markets, it has spread out into additive manufacturing (3D printing), biomaterials, composites, adhesives, graphic arts, thick samples manufacturing, dental materials and so on. ${ }^{1-9}$ This ever growing applications require the development of environmental-friendly photopolymerization processes to cope with ever increasing environmental pressure, this is more and more studied with naturally derived monomers. ${ }^{10,11}$ Furthermore, the compatibility with legislations and biomaterials applications point out that photoinitiating systems will have to be more and more naturally derived.

This is not the case today as most of industrial and academic photoinitiating systems are purely synthetic. $^{12}$ A few exception exists such as Bacteriochlorophyll and curcumin. ${ }^{13,14}$ However, there is still some needs to be met and we have very recently reported the use of 3hydroxyflavone as an efficient photoinitiator for polymerization processes. ${ }^{15}$ In the present paper, we have carried out the work around the flavone functionality. Five new naturallyderived compounds (Scheme 1) will be studied as photoinitiating systems in the presence of $N$-phenylglycine (amino-acid derivative) and an iodonium salt (e.g. used in dental materials). Structure/reactivity/efficiency relationships will be proposed using several physical-chemical techniques (ESR, static quenching, UV-vis, RT-FTIR,...). Additionally, these compounds can immediately find application in thick samples 3D-printing (1 mm layer at once) for highly increased manufacturing speeds.

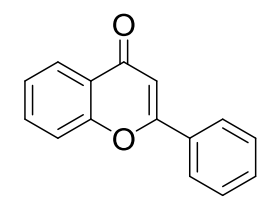

Flavone: F<smiles>O=c1cc(-c2ccccc2)oc2ccc(O)cc12</smiles>

6-Hydroxyflavone: $6 \mathrm{HF}$<smiles>O=c1cc(-c2ccccc2)oc2cc(O)ccc12</smiles>

7-Hydroxyflavone: 7HF<smiles>O=c1cc(-c2ccccc2)oc2cc(O)cc(O)c12</smiles>

Chrysin<smiles>CC(C)(C)C(C)(C)O</smiles>

Myricetin

Scheme 1. Flavone derivatives investigated in this study.

\section{Experimental part:}




\section{1) Chemical compounds:}

4-diphenylphosphinobenzoic acid (4-DPPBA), ethyl 4-(dimethylamino)benzoate (EDB), phenyl- $N$-tert-butylnitrone (PBN) and $N$-phenylglycine (NPG) were obtained from Sigma Aldrich (Scheme 2). Bis-(4-tert-butylphenyl)iodonium hexafluorophosphate (Iod or Speedcure 938) was obtained from Lambson Ltd (UK). Trimethylolpropane triacrylate (TMPTA) was obtained from Allnex and used as benchmark acrylate monomer for free radical polymerization. Bisphenol A-glycidyl methacrylate (BisGMA) and triethyleneglycol dimethacrylate (TEGDMA) were obtained from Sigma Aldrich and used with the highest purity available. For the family of flavones, all these compounds are purchased from TCI.<smiles>CCOC(=O)c1ccc(N(C)c2ccccc2)cc1</smiles>

EDB

NPG

lod

PBN

4-DPPBA<smiles>C=C(C)C(=O)OCCOCCOCCOC(=O)C(=C)C</smiles><smiles>C=CC(=O)OCC(CC)(COC(=O)C=C)COC(=O)C=C</smiles>

TMPTA

Scheme 2. Other used chemical compounds.

\section{2) Irradiation sources:}

The following Light Emitting Diodes (LEDs) were used as irradiation sources: i) LED@385 nm - incident light intensity at the sample surface: $\mathrm{I}_{0} \approx 80 \mathrm{~mW} \mathrm{~cm}$; ii) LED@405nm $\left(\mathrm{I}_{0} \approx 110 \mathrm{~mW} \mathrm{~cm}{ }^{-2}\right)$.

\section{3) Free Radical Polymerization (FRP):}

The two and three-component photoinitiating systems (PISs) are mainly based on flavone/Iod $(0.5 \% / 1 \% \mathrm{w} / \mathrm{w})$, flavone/NPG $(0.5 \% / 1 \% \mathrm{w} / \mathrm{w})$, and flavone/Iod/NPG (or EDB) $(0.5 \% / 1 \% / 1 \% \mathrm{w} / \mathrm{w})$ for free radical polymerization FRP of (meth)acrylates. The weight percent of the photoinitiating system is calculated from the monomer content. The photosensitive thin formulations for the FRP of TMPTA ( $25 \mu \mathrm{m}$ of thickness) was done in laminate (the formulation is sandwiched between two polypropylene films to reduce the $\mathrm{O}_{2}$ 
inhibition). The $1.4 \mathrm{~mm}$ thick samples of BisGMA/TEGDMA were polymerized under air in a plastic mold of $\sim 1 \mathrm{~cm}$ diameter and $1.4 \mathrm{~mm}$ of thickness.

Solubility of compounds varies in the benchmark monomers used (see Table 1). The evolution of the double bond content of (meth)acrylate functions was continuously followed by real time FTIR spectroscopy (JASCO FTIR 4100) at about $1630 \mathrm{~cm}^{-1}$. The evolution of the methacrylate characteristic peak for the thick samples $(1.4 \mathrm{~mm})$ was followed in the near infrared range at $\sim 6160 \mathrm{~cm}^{-1}$.

The procedure used to monitor the photopolymerization profile has been described in detail in ${ }^{16,17}$.

\section{4) ESR spin trapping (ESR-ST) experiments:}

The ESR-ST experiments were carried out using an X-Band Magnettech Spectrometer. LED@405nm was used as irradiation source for triggering the production of radicals at room temperature (RT) under $\mathrm{N}_{2}$ saturated tert-Butylbenzene and trapped by phenyl- $N$-tertbutylnitrone $(\mathrm{PBN})$ according to a procedure described elsewhere in detail ${ }^{18,19}$. The ESR spectrum simulations were carried out with the PEST WINSIM program.

\section{5) Absorption Experiments:}

The UV-vis absorption properties of the compounds were studied using a JASCO V730 spectrometer.

\section{6) Fluorescence Experiments:}

The fluorescence properties of the compounds were studied using a JASCO FP-6200 spectrometer.

\section{7) Computational Procedure:}

Molecular orbital calculations were carried out with the Gaussian 03 suite of programs. The electronic absorption spectra for the different compounds were calculated with the timedependent density functional theory at the MPW1PW91/6-31G* level of theory on the relaxed geometries calculated at the UB3LYP/6-31G* level of theory.

\section{8) $3 D$ printing experiments:}

For 3D printing experiments, a laser diode of monochromatic visible light @ $405 \mathrm{~nm}$ (size of the spot $=50 \mu \mathrm{m}$ ) was used for the spatially controlled irradiation in laser write experiment, and a LED projector @ 405 nm (Thorlabs) was used for LED 3D polymerization. The photosensitive resin (various thickness) deposited onto a microscope slide was polymerized under air and the generated patterns analyzed by a numerical optical microscope (DSX-HRSU from OLYMPUS corporation) or by profilometry. 


\section{Results and Discussion:}

\section{1) Light absorption properties of flavones:}

The UV-vis absorption spectra of the flavones in methanol are depicted in Figure 1 (see also Table 1). These compounds are characterized by high extinction coefficients in the near UV but also the visible range (e.g. $6 \mathrm{HF} \sim 5500 \mathrm{M}^{-1} . \mathrm{cm}^{-1} @ 350 \mathrm{~nm}$, and Myricetin $\sim 4800 \mathrm{M}^{-}$ $\left.{ }^{1} . \mathrm{cm}^{-1} @ 405 \mathrm{~nm}\right)$. Remarkably, their absorptions are good to excellent in the $350-470 \mathrm{~nm}$ range. A good overlap with the emission spectra of the LED@405 nm mainly used in this work is achieved. The extinction coefficients of different flavones follow the following order @ 405nm: Myricetin $>7 \mathrm{HF}>$ Chrysin $>6 \mathrm{HF}>$ Flavone.

The optimized geometries as well as the frontier orbitals (Highest Occupied Molecular Orbital HOMO and Lowest Unoccupied Molecular Orbital LUMO) are shown in Figure 2. Both the HOMO and LUMO are strongly delocalized all over the $\pi$ system clearly showing a $\pi \rightarrow \pi^{*}$ lowest energy transition.

Figure 1. Absorption spectra of flavones in methanol.

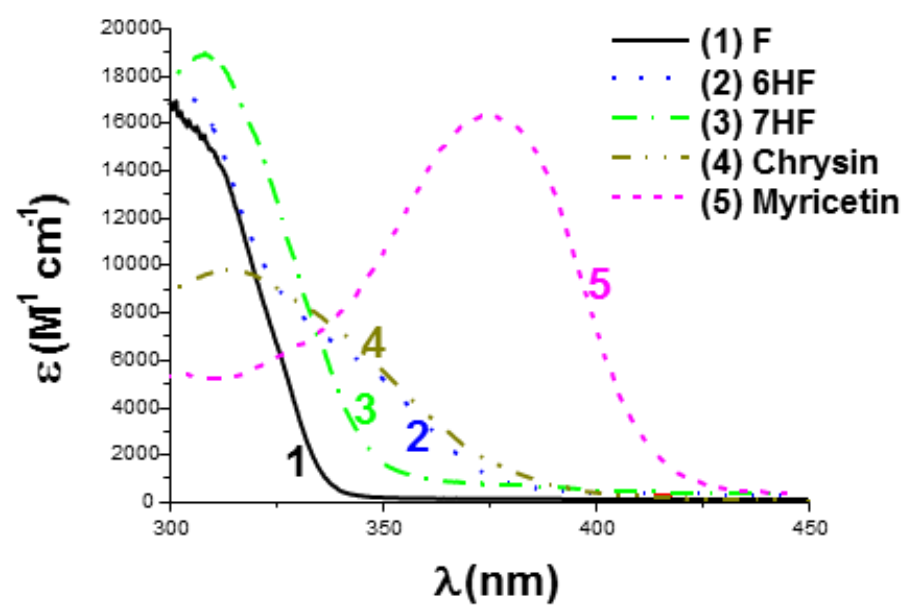

Table 1. Photochemical properties for flavones.

\begin{tabular}{|c|c|c|c|c|c|}
\hline & F & $6 \mathrm{HF}$ & $7 \mathrm{HF}$ & Chrysin & Myricetin \\
\hline $\begin{array}{c}\text { Absorption properties } \\
\varepsilon \lambda=405 \mathrm{~nm}\left(\mathrm{M}^{-1} \mathrm{~cm}^{-1}\right) \\
\text { in methanol }\end{array}$ & $\sim 70$ & $\sim 70$ & $\sim 427$ & $\sim 336$ & 4800 \\
\hline $\begin{array}{c}\text { Solubility in } \\
\text { BisGMA/TEGDMA }\end{array}$ & + & + & + & - & - \\
\hline
\end{tabular}


$+$

$+\quad+$

Figure 2. Contour plots of HOMOs and LUMOs for flavones optimized at the B3LYP/6$31 \mathrm{G}^{*}$ level of theory.

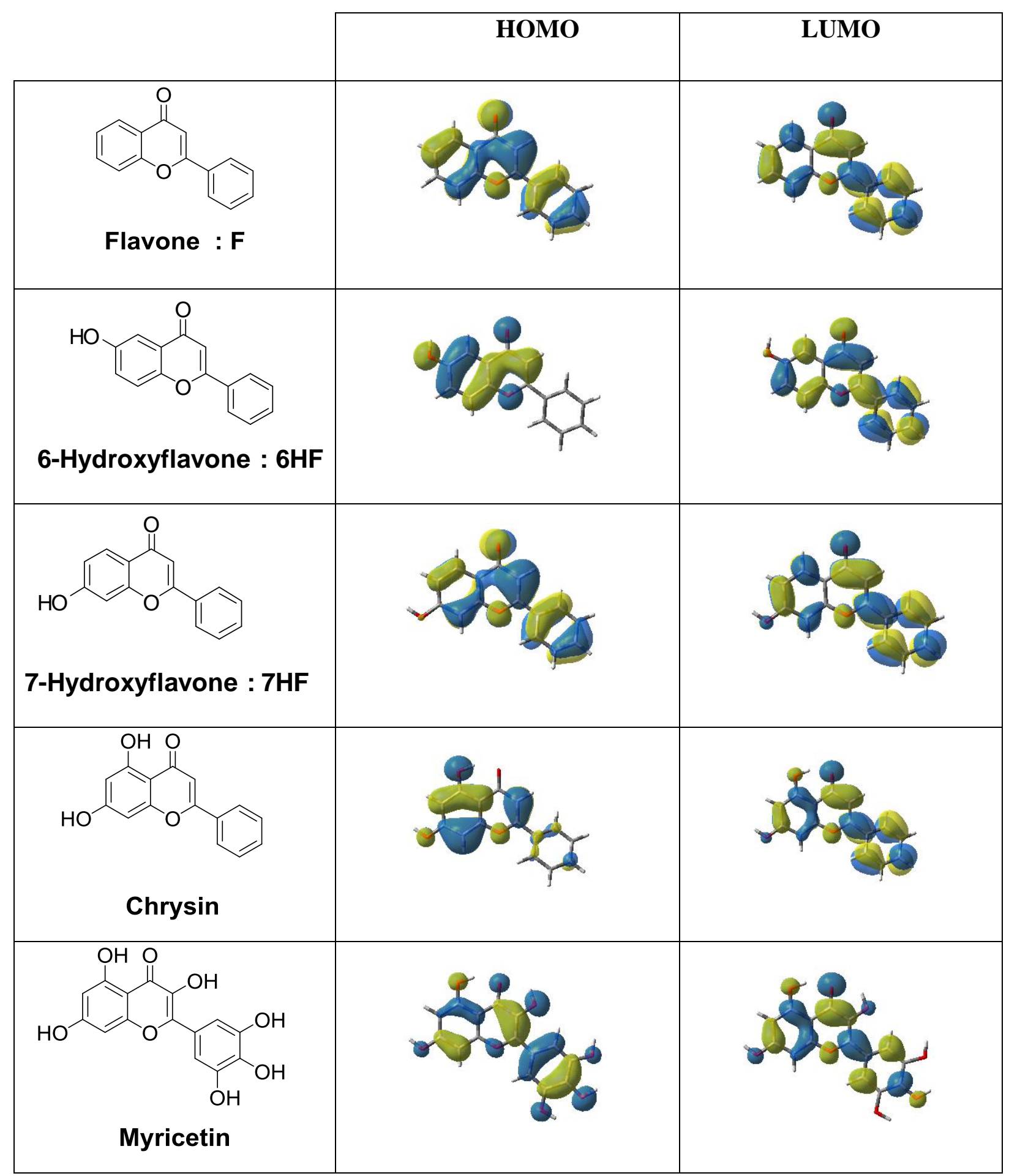




\section{2) Free Radical Photopolymerization:}

\subsection{Photopolymerization of acrylates (TMPTA):}

The FRP of TMPTA in thin films $(25 \mu \mathrm{m})$, in laminate, in the presence of the flavone/NPG or flavone/Iod/NPG couples is quite efficient using LED@385nm and LED@405nm, while Iod alone, or flavone/Iod combination do not activate the polymerization. Remarkably, a poor polymerization profile is observed for NPG alone in TMPTA when irradiated with LED@385nm (curve 11 Figure 3). This shows that flavone derivatives are quite efficient in a photo-reduction process (electron transfer from NPG to flavones). This efficient behavior will be discussed later in detail in the chemical mechanism part. Typical acrylate function conversion-time profiles for $6 \mathrm{HF}$ chosen as a template in different photoinitiating systems are given in Figure 3 and the final reactive function conversions (FCs) are summarized in Table 2. High FCs are reached in 6HF/NPG systems and 6HF/Iod/NPG systems (e.g. 6HF/NPG (0.5\%/1\% w/w), FC=36.6\% with LED@ 385nm curve 5 and 6HF/Iod/NPG $(0.5 \% / 1 \% / 1 \%$ w/w), FC= 40\% with LED@385nm curve 2 and $\mathrm{FC}=50 \%$ curve 1 with LED $@ 405 \mathrm{~nm}$ at $\mathrm{t}=100 \mathrm{~s}$ of thin sample $25 \mu \mathrm{m}$ in laminate; Figure 3 ). In comparison, the two-component system Iod/amine $(1 \% / 1 \% \mathrm{w} / \mathrm{w})$ shows almost no efficiency at least with LED@385nm for FRP thin samples (curve 9 Figure 3), highlighting the crucial role of $6 \mathrm{HF}$.

\section{Effect of additives:}

In fact, when NPG is replaced by Iod or EDB, no efficiency for $6 \mathrm{HF}$ based photoinitiating system was observed (curves 7, 8, and 10 in Figure 3 with different LEDs). This can be probably ascribed to the strong oxygen inhibition for the radical species generated in each case. To solve this issue, the phosphine known as 4-DPPBA (Scheme 2) was used, and in this case the efficiency increases from almost null with $6 \mathrm{HF} / \mathrm{Iod}(0.5 \% / 1 \% \mathrm{w} / \mathrm{w})$ curve 7 to reach $43 \%$ of conversion with $6 \mathrm{HF} / \mathrm{Iod} / 4-\mathrm{DPPBA}(0.5 \% / 1 \% / 1 \% \mathrm{w} / \mathrm{w})$ curve 13 with LED@385nm. Actually, Iod/4-DPPBA is reported ${ }^{20}$ to form a charge transfer complex (CTC) leading to $\mathrm{Ar}^{\bullet}$ formation able to initiate the FRP of acrylate upon irradiation with LED@385nm (Figure 3, curve 12, FC 18\%). This [4-DPPBA-Iod] $]_{\text {CTC }}$ is photosensitized herein with $6 \mathrm{HF}$, when $6 \mathrm{HF} / \mathrm{Iod} / 4-\mathrm{DPPBA}(0.5 \% / 1 \% / 1 \% \mathrm{w} / \mathrm{w})$ three-component system is used leading to increase in the final conversion ( $\mathrm{FC} \sim 43 \%)$.

\section{2) Photopolymerization of methacrylates:}


Interestingly, the flavone/NPG $(0.5 \% / 1 \% \mathrm{w} / \mathrm{w})$ couples efficiently initiate the FRP of a blend of methacrylates (BisGMA/TEGDMA 70\%/30\% w/w) (under air $1.4 \mathrm{~mm}$ thick sample considered for all systems of this part 2.2) (Figure 4) upon irradiation with LED@ 385nm and LED@405nm. Remarkably, tack-free polymers are obtained for thick samples under air with different bleaching properties.

In this part, a comparative study for the different flavones/NPG couples was carried out. In fact, the $6 \mathrm{HF} / \mathrm{NPG}$ system shows the best polymerization profile (methacrylate conversion FC for BisGMA/TEGDMA with 6HF/NPG $(0.5 \% / 1 \% \mathrm{w} / \mathrm{w})$ reached about $43 \%$ after $100 \mathrm{~s}$ of irradiation with LED@405nm) compared to lower efficiency observed with others (e.g. FC = $31 \%$ for $7 \mathrm{HF} / \mathrm{NPG}$ both $(0.5 \% / 1 \% \mathrm{w} / \mathrm{w})$ with LED @ $405 \mathrm{~nm}$ after $100 \mathrm{~s}$ of irradiation).

Table 2. Reactive function conversions (FC): acrylate for TMPTA and methacrylate for BisGMA/TEGDMA using different photoinitiating systems and irradiation conditions.

\begin{tabular}{|c|c|c|c|c|c|c|}
\hline Monomer/PIS & Conditions & $\mathbf{F}$ & $6 \mathrm{HF}$ & $7 \mathbf{H F}$ & Chrysin & Myricetin \\
\hline 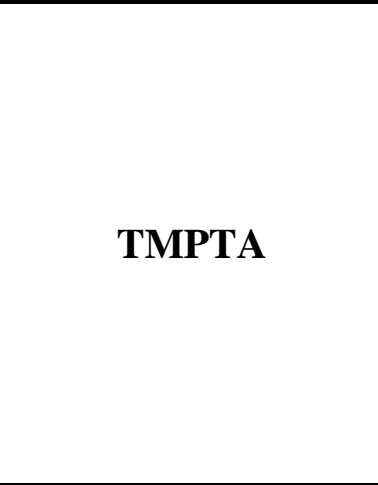 & $\begin{array}{c}\mathrm{a} \\
1 \mathrm{~b} \\
2 \mathrm{a} \\
2 \mathrm{~b} \\
3 \\
4 \mathrm{a} \\
4 \mathrm{~b} \\
5 \mathrm{a} \\
5 \mathrm{~b} \\
6\end{array}$ & & $\begin{array}{c}0 \% \\
0 \% \\
36.6 \% \\
7.4 \% \\
0 \% \\
50 \% \\
40 \% \\
34.8 \% \\
17.5 \% \\
43 \%\end{array}$ & & & \\
\hline 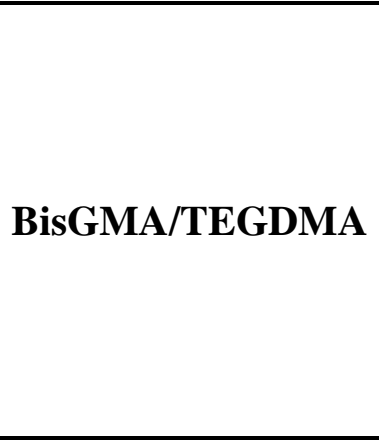 & $\begin{array}{c}7 \mathrm{a} \\
7 \mathrm{~b} \\
8 \mathrm{a} \\
8 \mathrm{~b} \\
9 \\
10 \mathrm{a} \\
10 \mathrm{~b} \\
11 \mathrm{a} \\
11 \mathrm{~b}\end{array}$ & $4 \%$ & $\begin{array}{c}36.7 \% \\
36.3 \% \\
43 \% \\
\\
4 \% \\
78.4 \% \\
\\
51.5 \% \\
56.6 \%\end{array}$ & $31.3 \%$ & $20 \%$ & $0 \%$ \\
\hline
\end{tabular}

1) Acrylate function conversion FC for TMPTA (\%) (at $\mathrm{t}=200 \mathrm{~s}$ in laminate) $(0.5 \% \mathrm{PI} / 1 \%$ Iod $\mathrm{w} / \mathrm{w}$; thickness $=$ $25 \mu \mathrm{m})(1 \mathrm{a})$ LED@385nm; (1b) LED@405nm. 2) FC for TMPTA (\%) (at $\mathrm{t}=200 \mathrm{~s}$ under air) $(0.5 \% \mathrm{PI} / 1 \% \mathrm{NPG}$ w/w $25 \mu \mathrm{m}$ ) (2a) LED@ 385nm; (2b) LED@ 405nm. 3) FC for TMPTA (\%) (at $\mathrm{t}=200 \mathrm{~s}$ under air) (0.5\% PI/1\% EDB w/w $25 \mu \mathrm{m}$ ) LED@405nm; 4) Acrylate function conversion FC for TMPTA (\%) (at $\mathrm{t}=200 \mathrm{~s}$ in laminate) (0.5\% PI/1\% Iod/1\%NPG w/w $25 \mu \mathrm{m})$ using (4a) LED@385nm; (4b) LED@405nm. 5) Acrylate function conversion FC for TMPTA (\%) (at $\mathrm{t}=200 \mathrm{~s}$ in laminate) $(0.5 \% \mathrm{PI} / 1 \% \operatorname{Iod} / 1 \% \mathrm{EDB}$ w/w $25 \mu \mathrm{m})(5 \mathrm{a})$ LED@385nm; (5b) LED@405nm. 6) Acrylate function conversion FC for TMPTA (\%) (at $\mathrm{t}=200 \mathrm{~s}$ in laminate) $(0.5 \% \mathrm{PI} / 1 \% \operatorname{Iod} / 1 \%$ 4-DPPBA w/w $25 \mu \mathrm{m})$ using LED @ $385 \mathrm{~nm}$. 7) Methacrylate function conversion FC for BisGMA/TEGDMA (\%) (at $\mathrm{t}=100 \mathrm{~s})(0.5 \%$ PI $/ 1 \%$ Iod w/w $1.4 \mathrm{~mm})$ using (7a) LED@385nm; (7b) LED@405nm. 8) Methacrylate function conversion FC for BisGMA/TEGDMA (\%) (at $\mathrm{t}=100 \mathrm{~s})(0.5 \% \mathrm{PI} / 1 \%$ NPG w/w $1.4 \mathrm{~mm}$ ) using (8a) LED@405nm, (8b) LED@477nm. 9) Methacrylate function conversion FC for BisGMA/TEGDMA $(\%)$ (at $\mathrm{t}=100 \mathrm{~s})$ under air $(0.5 \%$ PI/1\% EDB w/w $1.4 \mathrm{~mm})$ using LED@ $0505 \mathrm{~nm} ; 10)$ Methacrylate function conversion FC for BisGMA/TEGDMA (\%) (at $\mathrm{t}=100 \mathrm{~s}$ under air) $(0.5 \% \mathrm{PI} / 1 \%$ Iod/1\%NPG w/w 1.4mm) using (10a) LED@405nm, (10b) LED@477nm. 11) Methacrylate function conversion FC for BisGMA/TEGDMA (\%) (at $\mathrm{t}=100 \mathrm{~s}$ under air $(0.5 \% \mathrm{PI} / 1 \% \mathrm{Iod} / 1 \% \mathrm{EDB}$ w/w $1.4 \mathrm{~mm})$ using (11a) LED@385nm;(11b)LED@405nm. 
The efficiency trend in terms of BisGMA/TEGDMA methacrylate function conversion FC after 100s of irradiation with LED@405nm for different flavones/NPG $(0.5 \% / 1 \%$ w/w $)$ follows the following order: 6HF $>7 \mathrm{HF}>$ Chrysin $>$ Flavone $>$ Myricetin (Figure 4A; Table 2). Remarkably, this trend disobeys the order observed in the absorption properties. This will be discussed in the structure/efficiency/reactivity part.

On the other hand, NPG alone shows poor efficiency, and it is almost equivalent with chrysin/NPG system (curves 2 and 7; Figure 4A). Myricetin/NPG couple also shows no efficiency (FC is almost null as shown in curve 3), although NPG alone shows slight initiation ability. In fact, Myricetin solubility is very poor in methacrylates and is also reported as radical scavenger ${ }^{21}$ like other phenol-like structures (e.g. 4-Methoxyphenol).

\section{Effect of additives:}

Different couples including NPG, Iod, and EDB were studied. Before considering any flavone, the different additives were tested initially. In fact, Iod alone and EDB alone cannot initiate FRP. Iod/EDB (1\%/1\% w/w) couple also cannot initiate FRP upon exposure to LED@405nm (curve 9 Figure 4B). In contrast, Iod/NPG (1\%/1\% w/w) couple shows relatively high efficiency in FRP of methacrylate upon exposure to LED@405nm (FC =68\% curve 5 Figure 4B). This latter interaction probably corresponds to charge transfer complex formation (CTC) [NPG-Iod $]_{\text {CTC }}$ and will be discussed in the chemical mechanism part.

In this study, we will consider in detail the most efficient flavone as photoinitiator which is the leader of the efficiency trend (6HF). For $6 \mathrm{HF} / \mathrm{NPG}(0.5 \% / 1 \% \mathrm{w} / \mathrm{w})$ couple, as mentioned previously, high efficiency is shown up to 45\% using LED@405nm. In addition, an inhibition time was clearly observed at beginning of polymerization (curve 1 Figure 4A), which could be due to oxygen inhibition for methacrylate thick samples under air. However, with three-component system $6 \mathrm{HF} / \mathrm{NPG} / \mathrm{Iod}(0.5 \% / 1 \% / 1 \% \mathrm{w} / \mathrm{w})$ this conversion is enhanced up to $79 \%$ (curve 1 Figure 4B) under the same LED@405nm. In contrary, when replacing NPG with EDB, the $6 \mathrm{HF} / \mathrm{Iod} / \mathrm{EDB}(0.5 \% / 1 \%$ w/w) couple shows much lower conversion using LED@405nm (FC 58\% curve 4 Figure 4B). This show that, 6HF is a good photoinitiator through a three-component system involving NPG rather than EDB.

Figure 3. Polymerization profiles of TMPTA (acrylate function conversion vs. time) in laminate in the presence of three component photoinitiating system: 6HF/Iod/NPG (0.5\%/1\%/1\% w/w) upon exposure to LEDs: (1) @385 nm, (2) @405 nm; three component photoinitiating system: 6HF/Iod/EDB $(0.5 \% / 1 \% / 1 \% \mathrm{w} / \mathrm{w})$ upon exposure to LEDs: (3) @385 nm, (4)@405 nm ; two component photoinitiating system: 6-hydroxyflavone/NPG $(0.5 \% / 1 \%$ w/w) upon exposure to LEDs: (5) @385 nm; and (6) @405 nm, and 6-hydroxyflavone/Iod 
(0.5\%/1\% w/w) upon exposure to LEDs: (7) @ 385 nm; and (8) @ 405 nm; (9) two component photoinitiating system: Iod/EDB (1\%/1\% w/w) upon exposure to LED@405 nm; (10) two component photoinitiating system $6 \mathrm{HF} / \mathrm{EDB}(0.5 \% / 1 \% \mathrm{w} / \mathrm{w})$ upon exposure to LED@ 405 $\mathrm{nm}$; one component photoinitiating system: NPG $(1 \% \mathrm{w} / \mathrm{w})$ upon exposure to LEDs: (11) @ $385 \mathrm{~nm}$. (12) two component photoinitiating system Iod/4-DPPBA (1\%/1\% w/w) upon exposure to LED@385 nm; (13) three component photoinitiating system 6HF/Iod/4-DPPBA $(0.5 \% / 1 \% / 1 \% \mathrm{w} / \mathrm{w})$ upon exposure to LED@385nm. Irradiation starts at $\mathrm{t}=10 \mathrm{~s}$.

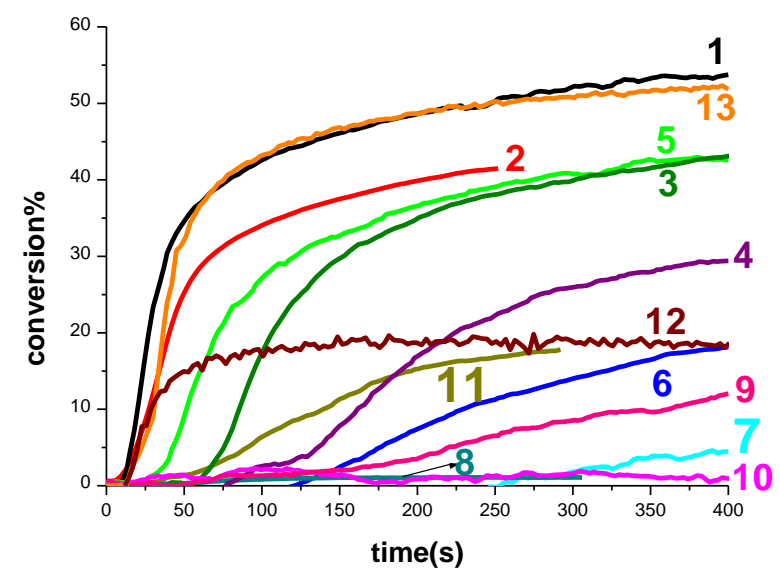

Figure 4. A) Polymerization profiles of BisGMA/TEGDMA (methacrylate function conversion vs. time) under air upon exposure to LED @ $405 \mathrm{~nm}$ in the presence of: (1) twocomponent photoinitiating system: 6-hydroxyflavone/NPG $(0.5 \% / 1 \% \quad \mathrm{w} / \mathrm{w}) ; \quad$ (2): Chrysin/NPG $\quad(0.5 \% / 1 \% \quad \mathrm{w} / \mathrm{w}) ; \quad(3): \quad$ Myricetin/NPG $\quad(0.5 \% / 1 \% \quad$ w/w $) ; \quad$ (4): $7-$ hydroxyflavone/NPG $(0.5 \% / 1 \% \mathrm{w} / \mathrm{w}) ;(5)$ : flavone/NPG $(0.5 \% / 1 \% \mathrm{w} / \mathrm{w}) ;(6)$ one component photoinitiating system: NPG $(1 \% \mathrm{w} / \mathrm{w})$; B) Polymerization profiles of BisGMA/TEGDMA under air in the presence of: (1) three-component photoinitiating system 6hydroxyflavone/Iod/NPG $(0.5 \% / 1 \% / 1 \%$ w/w) upon exposure to LED @ $405 \mathrm{~nm}$; (2) twocomponent photoinitiating system: 6-hydroxyflavone/NPG $(0.5 \% / 1 \% \mathrm{w} / \mathrm{w})$ upon exposure to LED@405 nm ; (3) three-component photoinitiating system: 6-hydroxyflavone/Iod/EDB $(0.5 \% / 1 \% / 1 \% \mathrm{w} / \mathrm{w})$ upon exposure to LED @385 nm ; (4) three-component photoinitiating system: 6-hydroxyflavone/Iod/EDB (0.5\%/1\%/1\% w/w) upon exposure to LED @ 405 nm (5) two-component photoinitiating system: Iod/NPG $(1 \% / 1 \% \mathrm{w} / \mathrm{w})$ upon exposure to LED @ 405 $\mathrm{nm}$; two-component photoinitiating system: 6-hydroxyflavone/Iod $(0.5 \% / 1 \% \mathrm{w} / \mathrm{w})$ with (6) LED@385nm, (7) LED@405nm; (8) two-component photoinitiating system: 6hydroxyflavone/EDB $(0.5 \% / 1 \%$ w/w) with LED@ $405 \mathrm{~nm}$, (9) two-component photoinitiating system: Iod/EDB (1\%/1\% w/w) upon exposure to LED @405 nm (10) one component photoinitiating system: NPG $(1 \%$ w/w) upon exposure to LED @385 nm . Irradiation starts at $\mathrm{t}=10 \mathrm{~s}$. 
A)

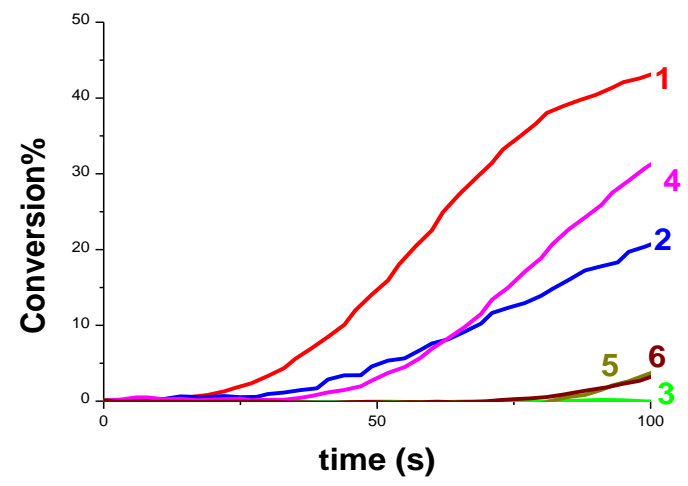

B)

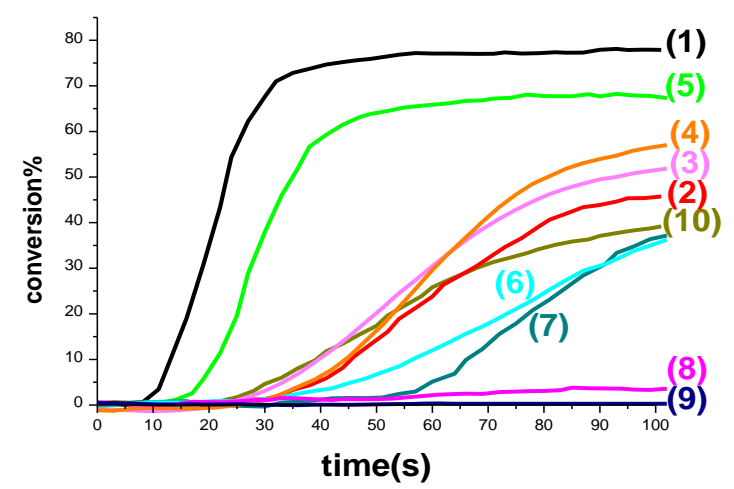

3) Cationic Photopolymerization (CP) of epoxides:

Upon irradiation with the LED@385 nm, it was found that the CP of epoxides under air using three-component photoinitiating systems based on 3-hydroxyflavone/Iod/EDB exhibited a very good efficiency. ${ }^{15}$ In this work, for the other flavones, a much lower performance than $3 \mathrm{HF}$ is found in these three-component systems, therefore these flavones were not investigated more in detail for cationic polymerization.

\section{4) 3D printing using 6HF/Iod/4-DPPBA based system upon LED@405nm projector:}

Using a LED projector @ 405nm (Thorlabs, $110 \mathrm{~mW} / \mathrm{cm}^{2}$ ), some 3D printing experiments were carried under air using the $6 \mathrm{HF} / \mathrm{Iod} / 4-\mathrm{DPPBA}(0.5 \% / 1 \% / 1 \% \mathrm{w} / \mathrm{w})$ system which was characterized by high reactivity in FRP (see above). Various 3D templates of different thicknesses were generated ( $30 \mu \mathrm{m}$ in Figure $5 \mathrm{~A}$ to $1.8 \mathrm{~mm}$ in Figure 5B). The LED projector technology is interesting compared to other laser-based 3D printing strategies as the entire layer is projected at one time. Thanks to numerical optical microscope, profilometric experiments were also carried out showing clearly the dimensions of the printed specimen (Figure $5 \mathrm{C}, \mathrm{D}$ ).

Figure 5. FRP experiments using a LED projector @ $405 \mathrm{~nm}$ : (A) letter ("n"), (B) cube, (C) Characterization in 3D by profilometry of "n" thin sample (30 $\mu$ m). (D) Characterization in 3D by profilometry of thick sample "cube" $(1800 \mu \mathrm{m})$ easily observed by using a numerical optical microscope. 
A)

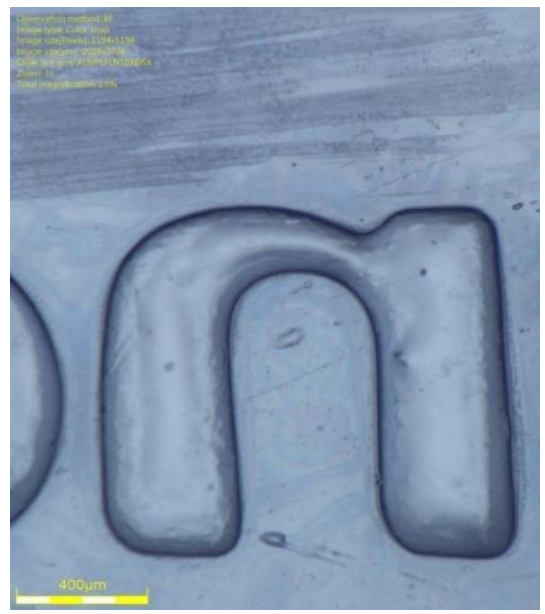

C)

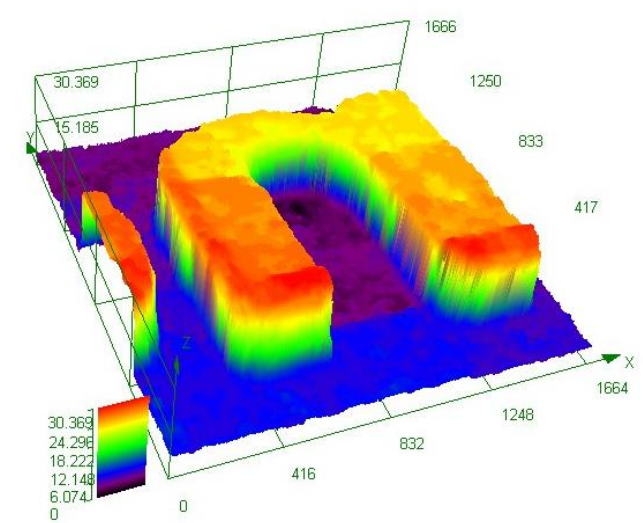

B)

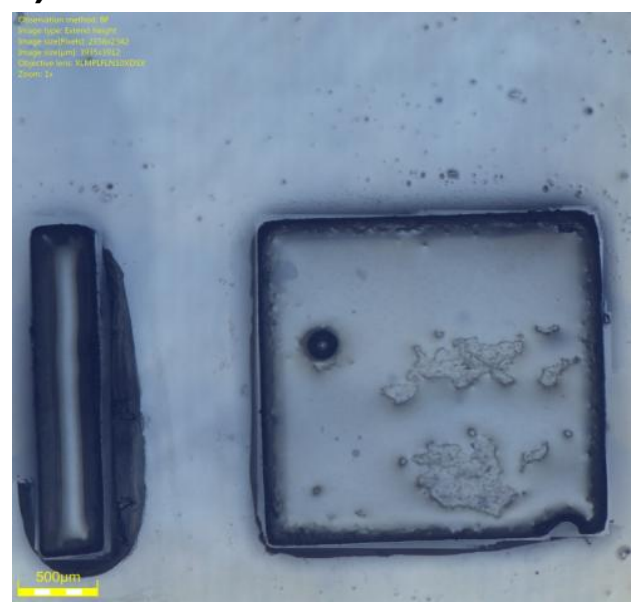

D)

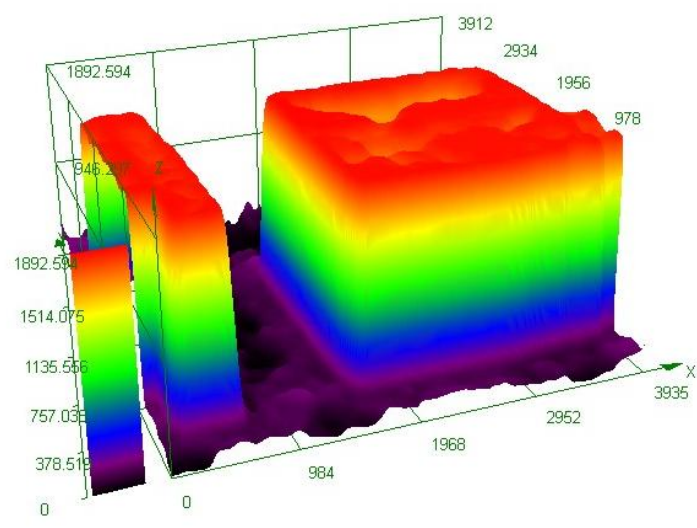

\section{5) Photochemical mechanisms:}

\subsection{Flavone/Iod and flavone/NPG interaction:}

Fluorescence experiments on 6HF in methanol were carried out. Fast fluorescence quenching processes of 6HF by NPG is noted (high value of the Stern-Volmer coefficient $\left(\mathrm{K}_{\mathrm{sv}}\right)$ of $6 \mathrm{HF} / \mathrm{NPG}$ interaction $\sim 2563 \mathrm{M}^{-1}$ vs $6 \mathrm{HF} / \mathrm{Iod}$ interaction $\sim 1580 \mathrm{M}^{-1}$; Figure 6$)$. This is in full agreement with photopolymerization kinetics results, which show much better performance of $6 \mathrm{HF} / \mathrm{NPG}$ over $6 \mathrm{HF} / \mathrm{Iod}$ combinations ( $\mathrm{r} 2$ faster than $\mathrm{r} 3$ ). In fact, the 6HF/NPG interaction corresponds to an electron transfer reaction finally leading to $\mathrm{NPG}_{(-\mathrm{H}, \text { - }}$ $\mathrm{CO} 2^{\bullet}$ ( $\mathrm{r} 1$ and $\left.\mathrm{r} 2\right) . \mathrm{NPG}_{(-\mathrm{H},-\mathrm{CO} 2)}{ }^{\bullet}$ can be considered as the initiating species for the free radical polymerization. $6 \mathrm{HF} / \mathrm{Iod}$ interaction is proposed to occur thanks to a redox reaction ${ }^{22}$ (r3) though its efficiency was lower than 6HF/NPG. Finally, it is proposed that NPG, an Naromatic electron donor, can form a CTC equilibrium with electron poor iodonium salt ( $\mathrm{r} 4)$ as what was recently published ${ }^{23}$ and confirmed experimentally (Figure S1). This [NPG-Iod] $]_{\text {CTC }}$ structure are quite convenient as they show enhanced visible light absorption and their 
photolysis at $405 \mathrm{~nm}$ leads to an efficient release of $\mathrm{Ar}^{\bullet}$ radicals (r5) as confirmed by photopolymerization study (Figure 4B curve 7).

On the other hand, the electron transfer quantum yields in the excited singlet state $\phi_{\mathrm{et}(\mathrm{S} 1)}$ were calculated (according eq 1; with higher $\phi_{\mathrm{et}(\mathrm{S} 1)} \sim 0.99$ of 6HF/NPG compared to 6HF/Iod $\sim 0.96$ ). These results are in agreement with photopolymerization kinetics results, which show better performance of $6 \mathrm{HF} / \mathrm{NPG}$ compared to $6 \mathrm{HF} / \mathrm{Iod}$ couple

$$
\begin{aligned}
& \phi_{\mathrm{et}(\mathrm{S} 1)}=\mathrm{K}_{\mathrm{sv}}[\text { Quencher }] /\left(1+\mathrm{K}_{\mathrm{sv}}[\text { Quencher }]\right) \\
& \text { Flavone } \rightarrow{ }^{1,3} \text { Flavone } \quad(h v) \\
& { }^{1,3} \text { Flavone }+\mathrm{NPG} \rightarrow \text { Flavone- } \mathrm{H}^{\bullet}+\mathrm{NPG}_{(-\mathrm{H})} \bullet \\
& \mathrm{NPG}_{(-\mathrm{H})} \bullet \rightarrow \mathrm{NPG}_{(-\mathrm{H},-\mathrm{CO} 2)} \stackrel{\bullet}{ }+\mathrm{CO}_{2} \\
& { }^{1,3} \text { Flavone }+\mathrm{Ar}_{2} \mathrm{I}^{+} \rightarrow \text { Flavone }^{\bullet+}+\mathrm{Ar}^{\bullet}+\mathrm{Ar}-\mathrm{I} \\
& \mathrm{NPG}+\operatorname{Iod} \leftrightarrow[\mathrm{NPG}-\mathrm{Iod}]_{\mathrm{CTC}} \\
& {[\mathrm{NPG}-\mathrm{Iod}]_{\mathrm{CTC}} \rightarrow \rightarrow \rightarrow \mathrm{Ar}^{\bullet}(\mathrm{h} v)}
\end{aligned}
$$

When irradiating a 6HF/Iod solution in ESR spin trapping experiments, aryl radicals are clearly observed in agreement with $\mathrm{r} 3$ (with hyperfine coupling constants $(h f c s): \mathrm{a}_{\mathrm{N}}=14.2 \mathrm{G}$ and $\mathrm{a}_{\mathrm{H}}=2.1 \mathrm{G}$; corresponding to literature data for $\mathrm{PBN} / \mathrm{Ar}^{\bullet}$ radical adduct). ${ }^{15}$

Figure 6. Stern Volmer treatment of 6HF fluorescence quenching with Iod vs. NPG.

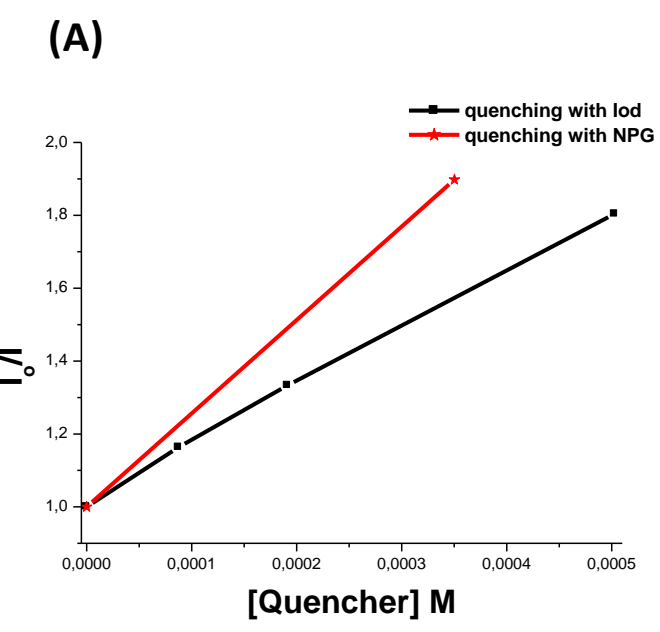

\subsection{Structure/reactivity/efficiency relationships.}

The UV visible spectra of different flavones cannot interpret the reactivity/efficiency in FRP. For example, Myricetin being the leader in the absorption properties, its character was 
the worst as photoinitiator. The number of phenolic (ArO-H) functionality appears as a key factor; indeed, the phenol group is a radical scavenger often used as inhibitor of radical processes. Therefore, the more functionalized is the flavone derivative and the more radical inhibitor is the structure. In this way, $6 \mathrm{HF}$ and $7 \mathrm{HF}$ are expected as the most reactive structure. Another factor affecting structure/reactivity/efficiency relationships can be ascribed to the solubility properties. For example, Myricetin shows poor solubility in meth(acrylate) formulations (see Table 1).

\section{Conclusion:}

Il this work, different flavone derivatives were studied. Interestingly, the threecomponent system with iodonium salt and N-phenylglycine is found rather efficient even for mild irradiation conditions. The flavone scaffold being observed in different natural dyes, this work paves the way for the development of new photoinitiating systems based on natural compounds. The use of these systems for composites and 3D printing applications will be presented in forthcoming works.

Acknowledgements: The Lebanese group would like to thank 'The Association of Specialization and Scientific Guidance' (Beirut, Lebanon) for funding and supporting this scientific work. The authors thank the "Agence Nationale de la Recherche" (ANR) for the grant "FastPrinting". 


\section{References: (Macromolecules style)}

(1) Crivello, J. V.; Dietliker, K. Photoinitiators for Free Radical Cationic \& Anionic Photopolymerisation; Wiley, 1999.

(2) Neckers, D. C.; Jager, W.; SITA Technology Limited. Chemistry \& Technology for UV \& EB Formulation for Coatings, Inks \& Paints, Photoinitiation for Polymerization: UV $\&$ EB at the Millenium; Wiley: Chichester, 1999.

(3) Moraes, R. R.; Faria-e-Silva, A. L.; Ogliari, F. A.; Correr-Sobrinho, L.; Demarco, F. F.; Piva, E. Impact of Immediate and Delayed Light Activation on Self-Polymerization of Dual-Cured Dental Resin Luting Agents. Acta Biomater. 2009, 5 (6), 2095-2100. https://doi.org/10.1016/j.actbio.2009.01.030.

(4) Palin, W. M.; Leprince, J. G.; Hadis, M. A. Shining a Light on High Volume Photocurable Materials. Dent. Mater. 2018, 34 (5), 695-710. https://doi.org/10.1016/j.dental.2018.02.009.

(5) Garra, P.; Dietlin, C.; Morlet-Savary, F.; Dumur, F.; Gigmes, D.; Fouassier, J. P.; Lalevée, J. Photopolymerization Processes of Thick Films and in Shadow Areas: A Review for the Access to Composites. Polym. Chem. 2017, 8 (46), 7088-7101. https://doi.org/10.1039/C7PY01778B.

(6) Garra, P.; Bonardi, A.-H.; Baralle, A.; Al Mousawi, A.; Bonardi, F.; Dietlin, C.; Morlet-Savary, F.; Fouassier, J.-P.; Lalevée, J. Monitoring Photopolymerization Reactions through Thermal Imaging: A Unique Tool for the Real-Time Follow-up of Thick Samples, 3D Printing, and Composites. J. Polym. Sci. Part Polym. Chem. 2018, 56 (8), 889-899. https://doi.org/10.1002/pola.28965.

(7) Lalevee, J.; Fouassier, J.-P. Photopolymerisation Initiating Systems; Polymer Chemistry Series; The Royal Society of Chemistry, 2018. https://doi.org/10.1039/9781788013307.

(8) Lalevée, J.; Fouassier, J.-P. Dyes and Chomophores in Polymer Science; John Wiley \& Sons, 2015.

(9) Dadashi-Silab, S.; Doran, S.; Yagci, Y. Photoinduced Electron Transfer Reactions for Macromolecular Syntheses. Chem. Rev. 2016, 116 (17), 10212-10275. https://doi.org/10.1021/acs.chemrev.5b00586.

(10) Gandini, A.; Lacerda, T. M. From Monomers to Polymers from Renewable Resources: Recent Advances. Top. Vol. Polym. Chem. 2015, 48, 1-39. https://doi.org/10.1016/j.progpolymsci.2014.11.002.

(11) Tehfe, M.-A.; Lalevée, J.; Gigmes, D.; Fouassier, J. P. Green Chemistry: SunlightInduced Cationic Polymerization of Renewable Epoxy Monomers Under Air. Macromolecules 2010, 43 (3), 1364-1370. https://doi.org/10.1021/ma9025702.

(12) Dumur, F.; Gigmes, D.; Fouassier, J.-P.; Lalevée, J. Organic Electronics: An El Dorado in the Quest of New Photocatalysts for Polymerization Reactions. Acc. Chem. Res. 2016, 49 (9), 1980-1989. https://doi.org/10.1021/acs.accounts.6b00227.

(13) Shanmugam, S.; Xu, J.; Boyer, C. Light-Regulated Polymerization under NearInfrared/Far-Red Irradiation Catalyzed by Bacteriochlorophyll a. Angew. Chem. Int. Ed. 2016, 55 (3), 1036-1040. https://doi.org/10.1002/anie.201510037.

(14) Zhao, J.; Lalevée, J.; Lu, H.; MacQueen, R.; Kable, S. H.; Schmidt, T. W.; Stenzel, M. H.; Xiao, P. A New Role of Curcumin: As a Multicolor Photoinitiator for Polymer Fabrication under Household UV to Red LED Bulbs. Polym. Chem. 2015, 6 (28), 50535061. https://doi.org/10.1039/C5PY00661A.

(15) Al Mousawi, A.; Garra, P.; Schmitt, M.; Toufaily, J.; Hamieh, T.; Graff, B.; Fouassier, J. P.; Dumur, F.; Lalevée, J. 3-Hydroxyflavone and N-Phenylglycine in High Performance Photoinitiating Systems for 3D Printing and Photocomposites Synthesis. Macromolecules 2018, 51 (12), 4633-4641. https://doi.org/10.1021/acs.macromol.8b00979. 
(16) Mousawi, A. A.; Kermagoret, A.; Versace, D.-L.; Toufaily, J.; Hamieh, T.; Graff, B.; Dumur, F.; Gigmes, D.; Fouassier, J. P.; Lalevée, J. Copper Photoredox Catalysts for Polymerization upon near UV or Visible Light: Structure/Reactivity/Efficiency Relationships and Use in LED Projector 3D Printing Resins. Polym. Chem. 2016, 8 (3), 568-580. https://doi.org/10.1039/C6PY01958G.

(17) Mousawi, A. A.; Dietlin, C.; Graff, B.; Morlet-Savary, F.; Toufaily, J.; Hamieh, T.; Fouassier, J. P.; Chachaj-Brekiesz, A.; Ortyl, J.; Lalevée, J. Meta-Terphenyl Derivative/Iodonium Salt/9H-Carbazole-9-Ethanol Photoinitiating Systems for Free Radical Promoted Cationic Polymerization upon Visible Lights. Macromol. Chem. Phys. 2016, 217 (17), 1955-1965. https://doi.org/10.1002/macp.201600224.

(18) Al Mousawi, A.; Dumur, F.; Garra, P.; Toufaily, J.; Hamieh, T.; Graff, B.; Gigmes, D.; Fouassier, J. P.; Lalevée, J. Carbazole Scaffold Based Photoinitiator/Photoredox Catalysts: Toward New High Performance Photoinitiating Systems and Application in LED Projector 3D Printing Resins. Macromolecules 2017, 50 (7), 2747-2758. https://doi.org/10.1021/acs.macromol.7b00210.

(19) Al Mousawi, A.; Dumur, F.; Garra, P.; Toufaily, J.; Hamieh, T.; Goubard, F.; Bui, T.T.; Graff, B.; Gigmes, D.; Pierre Fouassier, J.; et al. Azahelicenes as Visible Light Photoinitiators for Cationic and Radical Polymerization: Preparation of Photoluminescent Polymers and Use in High Performance LED Projector 3D Printing Resins. J. Polym. Sci. Part Polym. Chem. 2017, 55 (7), 1189-1199. https://doi.org/10.1002/pola.28476.

(20) P. Garra, et al, Macromolecules, 2016, 24, 9371-9381.

(21) Benov, L.; Georgiev, N. The Antioxidant Activity of Flavonoids Isolated from Corylus Colurna. Phytother. Res. 1994, $8 \quad$ (2), 92-94. https://doi.org/10.1002/ptr.2650080208.

(22) N. Zivic, M. Bouzrati-Zerelli, A. Kermagoret, F. Dumur, J.-P. Fouassier, D. Gigmes and J. Lalevée, ChemCatChem, 2016, 8, 1617-1631.

(23) P. Garra, B. Graff, F. Morlet-Savary, C. Dietlin, J.-M. Becht, J.-P. Fouassier and J. Lalevée, Macromolecules, 2018, 51, 57-70.

\section{References: (polymer chemistry style)}

1 J. V. Crivello and K. Dietliker, Photoinitiators for Free Radical Cationic \& Anionic Photopolymerisation, Wiley, 1999.

2 D. C. Neckers, W. Jager and SITA Technology Limited, Chemistry \& Technology for UV \& EB Formulation for Coatings, Inks \& Paints, Photoinitiation for Polymerization: UV \& EB at the Millenium, Wiley, Chichester, 1999.

3 R. R. Moraes, A. L. Faria-e-Silva, F. A. Ogliari, L. Correr-Sobrinho, F. F. Demarco and E. Piva, Acta Biomater., 2009, 5, 2095-2100.

4 W. M. Palin, J. G. Leprince and M. A. Hadis, Dent. Mater., 2018, 34, 695-710.

5 P. Garra, C. Dietlin, F. Morlet-Savary, F. Dumur, D. Gigmes, J. P. Fouassier and J. Lalevée, Polym. Chem., 2017, 8, 7088-7101.

6 P. Garra, A.-H. Bonardi, A. Baralle, A. Al Mousawi, F. Bonardi, C. Dietlin, F. MorletSavary, J.-P. Fouassier and J. Lalevée, J. Polym. Sci. Part Polym. Chem., 2018, 56, 889899.

7 J. Lalevee and J.-P. Fouassier, Photopolymerisation Initiating Systems, The Royal Society of Chemistry, 2018.

8 J. Lalevée and J.-P. Fouassier, Dyes and Chomophores in Polymer Science, John Wiley \& Sons, 2015.

9 S. Dadashi-Silab, S. Doran and Y. Yagci, Chem. Rev., 2016, 116, 10212-10275. 
10 A. Gandini and T. M. Lacerda, Top. Vol. Polym. Chem., 2015, 48, 1-39.

11 M.-A. Tehfe, J. Lalevée, D. Gigmes and J. P. Fouassier, Macromolecules, 2010, 43, 1364 1370.

12F. Dumur, D. Gigmes, J.-P. Fouassier and J. Lalevée, Acc. Chem. Res., 2016, 49, 19801989.

13 S. Shanmugam, J. Xu and C. Boyer, Angew. Chem. Int. Ed., 2016, 55, 1036-1040.

14J. Zhao, J. Lalevée, H. Lu, R. MacQueen, S. H. Kable, T. W. Schmidt, M. H. Stenzel and P. Xiao, Polym. Chem., 2015, 6, 5053-5061.

15 A. Al Mousawi, P. Garra, M. Schmitt, J. Toufaily, T. Hamieh, B. Graff, J. P. Fouassier, F. Dumur and J. Lalevée, Macromolecules, 2018, 51, 4633-4641.

16A. A. Mousawi, A. Kermagoret, D.-L. Versace, J. Toufaily, T. Hamieh, B. Graff, F. Dumur, D. Gigmes, J. P. Fouassier and J. Lalevée, Polym. Chem., 2016, 8, 568-580.

17 A. A. Mousawi, C. Dietlin, B. Graff, F. Morlet-Savary, J. Toufaily, T. Hamieh, J. P. Fouassier, A. Chachaj-Brekiesz, J. Ortyl and J. Lalevée, Macromol. Chem. Phys., 2016, 217, 1955-1965.

18 A. Al Mousawi, F. Dumur, P. Garra, J. Toufaily, T. Hamieh, B. Graff, D. Gigmes, J. P. Fouassier and J. Lalevée, Macromolecules, 2017, 50, 2747-2758.

19A. Al Mousawi, F. Dumur, P. Garra, J. Toufaily, T. Hamieh, F. Goubard, T.-T. Bui, B. Graff, D. Gigmes, J. Pierre Fouassier and J. Lalevée, J. Polym. Sci. Part Polym. Chem., 2017, 55, 1189-1199.

20 P. Garra, et al, Macromolecules, 2016, 24, 9371-9381.

21 Benov, L.; Georgiev, N. The Antioxidant Activity of Flavonoids Isolated from Corylus Colurna. Phytother. Res. 1994, 8 (2), 92-94. https://doi.org/10.1002/ptr.2650080208.

22 N. Zivic, M. Bouzrati-Zerelli, A. Kermagoret, F. Dumur, J.-P. Fouassier, D. Gigmes and J. Lalevée, ChemCatChem, 2016, 8, 1617-1631.

23 P. Garra, B. Graff, F. Morlet-Savary, C. Dietlin, J.-M. Becht, J.-P. Fouassier and J. Lalevée, Macromolecules, 2018, 51, 57-70.

\section{References: (journal of polymer science part a style)}

1. Crivello, J. V., Dietliker, K. Photoinitiators for Free Radical Cationic \& Anionic Photopolymerisation, Wiley, 1999.

2. Neckers, D. C., Jager, W., SITA Technology Limited Chemistry \& Technology for UV \& EB Formulation for Coatings, Inks \& Paints, Photoinitiation for Polymerization: UV \& EB at the Millenium, Wiley, Chichester, 1999.

3. Moraes, R. R., Faria-e-Silva, A. L., Ogliari, F. A., Correr-Sobrinho, L., Demarco, F. F., Piva, E. Acta Biomater., 2009, 5, 2095-2100.

4. Palin, W. M., Leprince, J. G., Hadis, M. A. Dent. Mater., 2018, 34, 695-710.

5. Garra, P., Dietlin, C., Morlet-Savary, F., Dumur, F., Gigmes, D., Fouassier, J. P., Lalevée, J. Polym. Chem., 2017, 8, 7088-7101.

6. Garra, P., Bonardi, A.-H., Baralle, A., Al Mousawi, A., Bonardi, F., Dietlin, C., MorletSavary, F., Fouassier, J.-P., Lalevée, J. J. Polym. Sci. Part Polym. Chem., 2018, 56, 889899.

7. Lalevee, J., Fouassier, J.-P. Photopolymerisation Initiating Systems, The Royal Society of Chemistry, 2018.

8. Lalevée, J., Fouassier, J.-P. Dyes and Chomophores in Polymer Science, John Wiley \& Sons, 2015.

9. Dadashi-Silab, S., Doran, S., Yagci, Y. Chem. Rev., 2016, 116, 10212-10275. 
10. Gandini, A., Lacerda, T. M. Top. Vol. Polym. Chem., 2015, 48, 1-39.

11. Tehfe, M.-A., Lalevée, J., Gigmes, D., Fouassier, J. P. Macromolecules, 2010, 43, 1364-1370.

12. Dumur, F., Gigmes, D., Fouassier, J.-P., Lalevée, J. Acc. Chem. Res., 2016, 49, 19801989.

13. Shanmugam, S., Xu, J., Boyer, C. Angew. Chem. Int. Ed., 2016, 55, 1036-1040.

14. Zhao, J., Lalevée, J., Lu, H., MacQueen, R., Kable, S. H., Schmidt, T. W., Stenzel, M. H., Xiao, P. Polym. Chem., 2015, 6, 5053-5061.

15. Al Mousawi, A., Garra, P., Schmitt, M., Toufaily, J., Hamieh, T., Graff, B., Fouassier, J. P., Dumur, F., Lalevée, J. Macromolecules, 2018, 51, 4633-4641.

16. Mousawi, A. A., Kermagoret, A., Versace, D.-L., Toufaily, J., Hamieh, T., Graff, B., Dumur, F., Gigmes, D., Fouassier, J. P., Lalevée, J. Polym. Chem., 2016, 8, 568-580.

17. Mousawi, A. A., Dietlin, C., Graff, B., Morlet-Savary, F., Toufaily, J., Hamieh, T., Fouassier, J. P., Chachaj-Brekiesz, A., Ortyl, J., Lalevée, J. Macromol. Chem. Phys., 2016, 217, 1955-1965.

18. Al Mousawi, A., Dumur, F., Garra, P., Toufaily, J., Hamieh, T., Graff, B., Gigmes, D., Fouassier, J. P., Lalevée, J. Macromolecules, 2017, 50, 2747-2758.

19. Al Mousawi, A., Dumur, F., Garra, P., Toufaily, J., Hamieh, T., Goubard, F., Bui, T.T., Graff, B., Gigmes, D., Pierre Fouassier, J., Lalevée, J. J. Polym. Sci. Part Polym. Chem., 2017, 55, 1189-1199.

20. Benov, L., Georgiev, N. Phytother. Res., 1994, 8, 92-94

(20) P. Garra, et al, Macromolecules, 2016, 24, 9371-9381.

(21) Benov, L.; Georgiev, N. The Antioxidant Activity of Flavonoids Isolated from $\begin{array}{llllll}\text { Corylus Colurna. } & \text { Phytother. Res. 1994, } 8 \text { (2), }\end{array}$ https://doi.org/10.1002/ptr.2650080208.

(22) N. Zivic, M. Bouzrati-Zerelli, A. Kermagoret, F. Dumur, J.-P. Fouassier, D. Gigmes and J. Lalevée, ChemCatChem, 2016, 8, 1617-1631.

(23) P. Garra, B. Graff, F. Morlet-Savary, C. Dietlin, J.-M. Becht, J.-P. Fouassier and J. Lalevée, Macromolecules, 2018, 51, 57-70. 